\title{
Repeated Cocaine Modifies the Mechanism by which Amphetamine Releases Dopamine
}

\author{
R. Christopher Pierce and Peter W. Kalivas \\ Alcohol and Drug Abuse Program, Washington State University, Pullman, Washington 99164-6520
}

This study determined whether daily cocaine administration initiates a calcium requirement for the increase in extracellular dopamine produced by psychostimulants. The increase in extracellular dopamine induced by perfusion of amphetamine through a microdialysis probe in the nucleus accumbens shell was enhanced in cocaine- relative to saline-pretreated rats. The augmented portion of the amphetamine-induced increase in nucleus accumbens dopamine was abolished by the coperfusion of L- or N-type calcium channel blockers. Inhibition of calcium/calmodulin-dependent protein kinase II (CaM-KII) also prevented the augmented increase in dopamine by amphetamine, whereas inhibition of vesicular exocytosis by botulinum toxin B was ineffective. When the concentration of extracellular dopamine in the nucleus accumbens was elevated by blocking the plasmallemal dopamine transporter with GBR-12909, the augmented increase in extracellular dopamine in rats sensitized to repeated cocaine was blocked by a CaM-KII inhibitor. Pretreatment with botulinum toxin B prevented the increase in extracellular dopamine by GBR-12909 in both cocainepretreated and control rats. Taken together, these results demonstrate that the psychostimulant-induced enhanced increase in extracellular dopamine in the nucleus accumbens shell of cocaine-pretreated rats arises from the induction of calciumand CaM-KII-dependent mechanisms.

Key words: behavioral sensitization; cocaine; amphetamine; GBR-12909; verapamil; conotoxin; diltiazem; KN-93; botulinum toxin; calcium; calmodulin
The abuse of amphetamine-like psychostimulants is a medical and social problem throughout the world. The behavioral stimulant and reinforcing properties of amphetamine-like stimulants are linked to the capacity of these drugs to increase extracellular concentrations of dopamine in the forebrain, notably in the nucleus accumbens (Wise and Bozarth, 1987; Koob and Bloom, 1988; Nestler, 1992; Di Chiara, 1995). Psychostimulant abuse can result in the emergence of psychopathologies such as paranoid psychosis and panic attacks, and altered forebrain dopamine transmission is linked to the development of these behavioral changes (Ellinwood, 1967; Segal et al., 1981; Post and Weiss, 1988). Similarly, in an animal model of this form of behavioral sensitization, the repeated administration of amphetamine-like psychostimulants in rats increases the capacity of amphetamine to induce motor activity and increase extracellular dopamine in the nucleus accumbens, particularly after extended withdrawal periods (Kalivas and Duffy, 1993; Wolf et al., 1993; Paulson and Robinson, 1995).

Recent findings indicate that calcium-dependent protein kinases are critically involved in activity-dependent synaptic modifications (Calabresi et al., 1994; Lisman, 1994). It has been reported that calcium also plays an important role in the behavioral plasticity observed after repeated exposure to psychostimulants. Thus, in contrast to the acute behavioral effect of amphetamine or cocaine, the sensitized motor response after repeated psychostimulant treatment is blocked by the systemic

Received Oct. 28, 1996; revised Feb. 3, 1997; accepted Feb. 6, 1997.

This research was supported in part by the Washington State Alcohol and Drug Abuse Program and U.S. Public Health Service Grants MH-40817, DA-03906, Research Career Development Award DA-00158 (P.W.K.), and National Research Service Award DA-05589 (R.C.P.).

Correspondence should be addressed to Dr. Chris Pierce, Department of VCAPP Washington State University, Pullman, WA 99164-6520.

Copyright (C) 1997 Society for Neuroscience $0270-6474 / 97 / 173254-08 \$ 05.00 / 0$ administration of L-type calcium channel antagonists (Pani et al., 1990; Karler et al., 1991; Martin-Iverson and Reimer, 1994). The fact that calcium channel antagonists inhibit the expression of behavioral sensitization, but not the acute drug effect, poses the possibility that the repeated administration of psychostimulants may modify the mechanism of amphetamineinduced dopamine release by invoking a requirement for calcium. Indeed, a recent microdialysis study indicated that replacing calcium with magnesium in the dialysis buffer inhibited the augmented increase in extracellular dopamine in the nucleus accumbens of rats pretreated with repeated amphetamine (Warburton et al., 1996). Furthermore, among cocainepretreated animals, the systemic administration of the L-type calcium channel antagonist, nimodipine, attenuated the enhanced increase in dopamine in the striatum resulting from a peripheral cocaine injection (Pani et al., 1990).

To appraise potential mechanisms underlying the calcium requirement for the augmented increase in extracellular dopamine in cocaine-sensitized animals, the present study estimated the effects of various compounds that block calcium channels or inhibit calcium-calmodulin-stimulated kinases on the increase in extracellular dopamine in the nucleus accumbens shell produced by psychostimulants. Two psychostimulants were used: GBR12909, which blocks the dopamine transporter in a manner similar to cocaine (Van der Zee et al., 1980; Nomikos et al., 1990), and amphetamine, which induces dopamine release by exchange diffusion (see Seiden et al., 1993). GBR-12909 was substituted for cocaine in all experiments in which the drug was administered via the microdialysis probe because of the local anesthetic property of cocaine. The role of calcium-mediated vesicular exocytosis also was evaluated by pretreating animals with botulinum toxin B before assessing the effects of amphetamine or GBR-12909. 


\begin{tabular}{|c|c|c|c|c|}
\hline & $n$ & Day $1^{a}$ & Day 7 & Statistics $^{b}$ \\
\hline \multicolumn{5}{|c|}{ Amphetamine } \\
\hline Saline & 13 & $7973(658)^{c}$ & 9907 (2032) & $t(12)=0.929, p=0.3711$ \\
\hline Cocaine & 12 & $11513(1464)$ & $20039(2565)$ & $t(11)=02.39, p=0.0358$ \\
\hline \multicolumn{5}{|l|}{ GBR-12909 } \\
\hline Saline & 9 & $4747(467)$ & $7588(1063)$ & $t(8)=02.42, p=0.0422$ \\
\hline Cocaine & 8 & $13119(2159)$ & $25159(3574)$ & $t(7)=03.04, p<0.0188$ \\
\hline \multicolumn{5}{|c|}{ Amphetamine + verapamil } \\
\hline Saline & 7 & 4002 (627) & $6840(533)$ & $t(6)=03.45, p=0.0136$ \\
\hline Cocaine & 9 & $14402(1627)$ & $25123(1755)$ & $t(8)=09.14, p=0.0001$ \\
\hline \multicolumn{5}{|c|}{ Amphetamine + diltiazem } \\
\hline Saline & 10 & 4035 (1036) & $5322(762)$ & $t(9)=01.14, p=0.2822$ \\
\hline Cocaine & 10 & $13738(2212)$ & 19085 (7247) & $t(9)=02.99, p=0.0153$ \\
\hline \multicolumn{5}{|c|}{ Amphetamine $+\omega$-conotoxin } \\
\hline Saline & 10 & $4419(360)$ & $5627(907)$ & $t(9)=01.36, p=0.2064$ \\
\hline Cocaine & 8 & $13460(2352)$ & 21193 (3793) & $t(7)=02.55, p=0.0382$ \\
\hline \multicolumn{5}{|c|}{ Botulinum toxin-amphetamine } \\
\hline Saline & 7 & $5894(1029)$ & $6418(1164)$ & $t(6)=0.452, p=0.6673$ \\
\hline Cocaine & 10 & $15096(3380)$ & $21260(4325)$ & $t(9)=01.30, p=0.2265$ \\
\hline \multicolumn{5}{|c|}{ Botulinum toxin-GBR-12909 } \\
\hline Saline & 6 & $3466(146)$ & $5962(1245)$ & $t(5)=01.89, p=0.1168$ \\
\hline Cocaine & 6 & $11826(4786)$ & $32261(4093)$ & $t(5)=07.66, p=0.0006$ \\
\hline \multicolumn{5}{|c|}{ Amphetamine $+\mathrm{KN}-93$} \\
\hline Saline & 9 & $3739(551)$ & $7578(1438)$ & $t(8)=02.53, p=0.0351$ \\
\hline Cocaine & 8 & $9266(2345)$ & $21481(2472)$ & $t(7)=04.28, p=0.0036$ \\
\hline \multicolumn{5}{|c|}{ Amphetamine $+\mathrm{KN}-92$} \\
\hline Saline & 9 & 7025 (902) & $5583(911)$ & $t(8)=01.13, p=0.2935$ \\
\hline Cocaine & 8 & $16799(3311)$ & $22599(4717)$ & $t(7)=01.14, p=0.2900$ \\
\hline \multicolumn{5}{|c|}{ GBR-12909 + KN-93 } \\
\hline Saline & 11 & $5928(953)$ & $9270(1324)$ & $t(10)=02.16, p=0.0558$ \\
\hline Cocaine & 16 & $12376(1975)$ & 19257 (2643) & $t(15)=01.93, p=0.0729$ \\
\hline
\end{tabular}

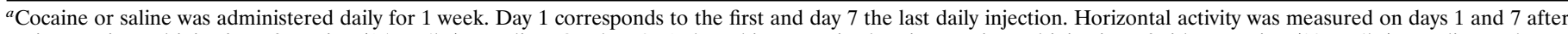

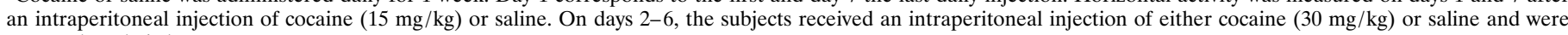
returned to their home cage.

${ }^{b}$ Paired $t$ test; degrees of freedom in parentheses.

${ }^{c}$ The data are presented as the total horizontal photocell counts (SE) recorded over the first 120 min after cocaine or saline injection.

\section{MATERIALS AND METHODS}

Subjects. All of the experiments described in this report were performed in accordance with the specifications of the Washington State University Animal Care and Use Committee. Male Sprague Dawley rats (Simmonsen Laboratories, Gilroy, CA) were individually housed with food and water available ad libitum. A $12 \mathrm{hr}$ light/dark cycle was used with the lights on at 6:30 A.M. All cocaine injections, behavioral testing, and microdialysis were performed during the light cycle.

Repeated cocaine or saline treatment. Equal numbers of subjects were assigned to the cocaine and saline groups. The day before the start of the experiment, all animals were habituated to the photocell boxes (Omnitech Electronics, Columbus, $\mathrm{OH}$ ) for $3 \mathrm{hr}$. On the first treatment day, all animals were habituated to the photocell boxes for $1 \mathrm{hr}$. After habituation, animals received either cocaine $(15 \mathrm{mg} / \mathrm{kg}$, i.p.; donated by the National Institute of Drug Abuse) or saline (1.0 ml $/ \mathrm{kg}$, i.p.), and behavior subsequently was monitored for $2 \mathrm{hr}$. On days $2-6$, rats received daily injections of cocaine $(30 \mathrm{mg} / \mathrm{kg}$, i.p.) or saline in the home cage. On the seventh day, all animals were again habituated to the photocell boxes for $1 \mathrm{hr}$. Cocaine $(15 \mathrm{mg} / \mathrm{kg})$ or saline then was administered i.p., and behavior was monitored for $2 \mathrm{hr}$.

Surgery. Stereotaxic implantation of a dialysis guide cannula was conducted 2 weeks after the last injection of cocaine or saline. Rats weighing 300 to $350 \mathrm{gm}$ were anesthetized with Equithesin $(3.0 \mathrm{ml} / \mathrm{kg})$ and mounted in a stereotaxic apparatus. A unilateral microdialysis guide cannula (12 mm, 20 gauge stainless steel) was implanted $2 \mathrm{~mm}$ dorsal to the nucleus accumbens shell $(1.0 \mathrm{~mm}$ anterior; $0.8 \mathrm{~mm}$ lateral relative to bregma; Paxinos and Watson, 1986) and cemented in place by affixing dental acrylic to three stainless steel screws that were tapped into the skull. There was 1 week of recovery from surgery before all microdialysis experiments.

Microdialysis and measurement of extracellular dopamine. The dialysis probes were constructed as described by Robinson and Whishaw (1988), with approximately $2.0 \mathrm{~mm}$ of active dialysis membrane exposed at the tip. The dialysis experiments were performed 21-22 days after the last daily cocaine injection. The evening before the experiment, the probes were inserted through the guide cannulae into the nucleus accumbens ( $8.0 \mathrm{~mm}$ ventral to the top of the skull). The next day, dialysis buffer (5 $\mathrm{mm} \mathrm{KCl}, 120 \mathrm{~mm} \mathrm{NaCl}, 1.2 \mathrm{mM} \mathrm{CaCl}_{2}, 1.2 \mathrm{mM} \mathrm{MgCl}_{2}, 5.0 \mathrm{~mm}$ glucose, plus $0.2 \mathrm{~mm}$ PBS to give a $\mathrm{pH}$ value of 7.4 and a final sodium concentration of $120.7 \mathrm{~mm}$ ) was advanced through the probe at a rate of 1.9 $\mu \mathrm{l} /$ min via a syringe pump (Harvard Instruments, Boston, MA). In the first two experiments, after $100 \mathrm{~min}$ of baseline, increasing concentrations of amphetamine $(0.1,1.0$, and $10.0 \mu \mathrm{M})$ or GBR-12909 (1.0, 10.0, and $100.0 \mu \mathrm{M})$ were incorporated into the dialysis buffer for $100 \mathrm{~min}$ each. The next series of experiments were designed to assess the effects of calcium channel antagonists on the amphetamine- and GBR-12909induced increase in dopamine. After baseline, one of the following drugs was included in the dialysis buffer for the duration of the experiment: the L-type calcium channel blockers verapamil $(100 \mu \mathrm{M}$; Research Biochemicals, Natick, MA) and diltiazem (10 $\mu \mathrm{M}$; Research Biochemicals), or the N-type channel blocker $\omega$-conotoxin (1 $\mu \mathrm{M}$; Research Biochemicals). After baseline and $100 \mathrm{~min}$ of one of the calcium channel antagonists alone, increasing concentrations of amphetamine $(0.1,1.0$, and $10.0 \mu \mathrm{M})$ or GBR-12909 $(1.0,10.0$, and $100.0 \mu \mathrm{M})$ were incorporated into the 
Table 2. Effects of calcium channel antagonists, KN-93, KN-92, or botulinum toxin B on the baseline concentration of extracellular dopamine in the nucleus accumbens shell

\begin{tabular}{|c|c|c|c|c|}
\hline & $n$ & Baseline $^{a}$ & Drug $^{b}$ & $\%$ Baseline \\
\hline \multicolumn{5}{|c|}{ Botulinum toxin-amphetamine ${ }^{c}$} \\
\hline Saline & $13 / 7$ & $39(7)$ & $19(4)^{*}$ & 49 \\
\hline Cocaine & $12 / 10$ & $41(8)$ & $12(2)^{*}$ & 29 \\
\hline \multicolumn{5}{|c|}{ Botulinum toxin-GBR-12909 } \\
\hline Saline & $9 / 6$ & $31(13)$ & $15(9)$ & 48 \\
\hline Cocaine & $8 / 6$ & $31(12)$ & $15(15)$ & 48 \\
\hline \multicolumn{5}{|c|}{ Amphetamine + verapamil } \\
\hline Saline & 7 & $42(10)$ & $29(8)^{*}$ & 69 \\
\hline Cocaine & 9 & $29(6)$ & $22(4)^{*}$ & 76 \\
\hline \multicolumn{5}{|c|}{ Amphetamine + diltiazem } \\
\hline Saline & 10 & $25(6)$ & $16(3)^{*}$ & 64 \\
\hline Cocaine & 10 & $54(15)$ & $40(18)$ & 74 \\
\hline \multicolumn{5}{|c|}{ Amphetamine + conotoxin } \\
\hline Saline & 10 & $25(7)$ & $16(3)^{*}$ & 64 \\
\hline Cocaine & 8 & $21(5)$ & $12(4)$ & 74 \\
\hline \multicolumn{5}{|c|}{ Amphetamine $+\mathrm{KN}-93$} \\
\hline Saline & 9 & $32(8)$ & $35(8)$ & 109 \\
\hline Cocaine & 8 & $33(5)$ & $38(6)$ & 115 \\
\hline \multicolumn{5}{|c|}{ Amphetamine $+\mathrm{KN}-92$} \\
\hline Saline & 9 & $51(10)$ & $63(11)$ & 124 \\
\hline Cocaine & 8 & $79(15)$ & $78(10)$ & 99 \\
\hline \multicolumn{5}{|c|}{ GBR-12909 + KN-93 } \\
\hline Saline & 11 & $25(3)$ & $29(5)$ & 116 \\
\hline Cocaine & 16 & $35(6)$ & $43(9)$ & 123 \\
\hline
\end{tabular}

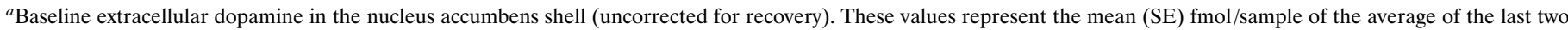
baseline samples (60-100 min from the onset of the experiment).

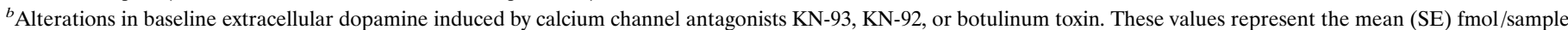

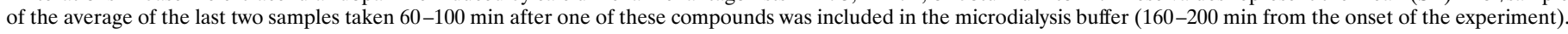

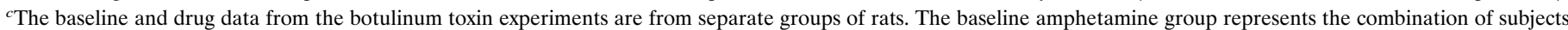

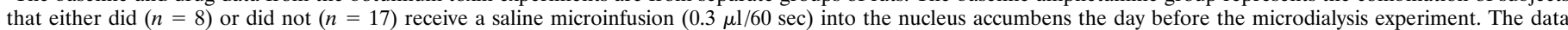

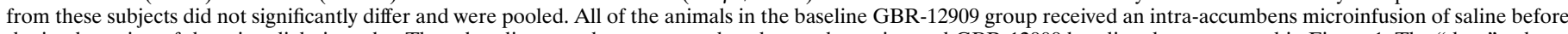

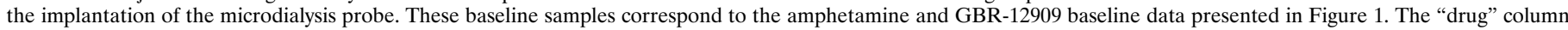

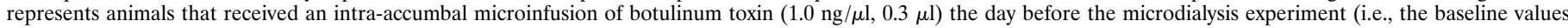
of the amphetamine and GBR-12909 experiments summarized in Fig. 3).

* Significant difference between the drug and baseline dopamine values ( $p<0.05, t$ test).

dialysis buffer for 100 min each. The effect of the CaM-KII inhibitor KN-93 also was assessed. After baseline and $100 \mathrm{~min}$ of KN-93 (10 $\mu \mathrm{M}$; Calbiochem, San Diego, CA) alone, increasing concentrations of amphetamine $(0.1,1.0$, and $10.0 \mu \mathrm{M})$ or GBR-12909 $(1.0,10.0$, and $100.0 \mu \mathrm{M})$ were incorporated into the dialysis buffer for $100 \mathrm{~min}$ each. The effect of the negative control compound for KN-93, KN-92, also was assessed. After baseline and $100 \mathrm{~min}$ of KN-92 (10 $\mu \mathrm{M}$; Calbiochem, San Diego, $\mathrm{CA})$ alone, increasing concentrations of amphetamine (0.1, 1.0 , and 10.0 $\mu \mathrm{M})$ were incorporated into the dialysis buffer for $100 \mathrm{~min}$ each. In the final experiments, the rats were pretreated with a microinfusion of botulinum toxin B $(1.0 \mathrm{ng} / \mu \mathrm{l}, 0.3 \mu \mathrm{l}$; Sigma, St. Louis, MO) or saline $(0.3 \mu \mathrm{l})$ into the nucleus accumbens $15 \mathrm{~min}$ before inserting the microdialysis probe. The next day, after $100 \mathrm{~min}$ of baseline, increasing concentrations of amphetamine $(0.1,1.0$, and $10.0 \mu \mathrm{M})$ or GBR-12909 $(1.0,10.0$, and $100.0 \mu \mathrm{M}$ ) were incorporated into the dialysis buffer for $100 \mathrm{~min}$ each. In all cases microdialysis samples were taken every $20 \mathrm{~min}$.

For the measurement of extracellular dopamine, samples were collected into microfuge tubes containing $20 \mu \mathrm{l}$ of mobile phase $(0.1 \mathrm{M}$ citric acid, $75 \mathrm{~mm} \mathrm{Na} \mathrm{HPO}_{4}, 1.5 \mathrm{~mm}$ heptanosulfonic acid, $0.1 \mathrm{~mm}$ EDTA, $15 \%$ methanol, v/v, $\mathrm{pH} 4.2$ ) plus $2.0 \mathrm{pmol}$ of dihydroxybenzylamine as an internal standard. After collection, all samples were frozen at $-80^{\circ} \mathrm{C}$ until analyzed. The samples were subsequently thawed and placed in an autosampler (Gilson Medical Supplies, Middleton, WI) connected to an HPLC system with electrochemical detection. The dopamine was separated using a $25 \mathrm{~cm} \mathrm{C}_{18}$ reversed phase column (Bioanalytical Systems, West LaFayette, IN) and oxidized/reduced using coulometric detection (ESA, Bedford, MA). Three electrodes were used: a preinjection port guard cell $(+0.4 \mathrm{~V})$ to oxidize the mobile phase, an oxidation analytical electrode $(+0.3 \mathrm{~V})$, and a reduction analytical electrode $(-0.14 \mathrm{~V})$. Peaks were recorded on a chart recorder and compared with an external standard curve $(10-1000 \mathrm{fmol})$.

Histology. After the dialysis experiment, the rats were given an overdose of pentobarbital (>100 mg/kg, i.p.) and perfused intracardially with PBS, followed by $10 \%$ formalin. The brain was removed and stored in $10 \%$ formalin for at least 1 week. The brains were then blocked, and coronal sections $(100 \mu \mathrm{m})$ were taken at the level of the nucleus accumbens with a vibratome. The sections were mounted on gelatin-coated slides and stained with cresyl violet. Probe and cannula placements were determined according to the atlas of Paxinos and Watson (1986) by an individual unaware of the behavioral or neurochemical response of the rats.

Data analysis. The effect of amphetamine or GBR-12909 on extracellular dopamine was evaluated using a two-way ANOVA with repeated measures over dose. Pairwise comparisons between cocaine and saline treatment groups were made with Fisher's LSD. The effect of calcium channel antagonists on basal extracellular levels of dopamine was examined by averaging the last two samples of baseline collection and comparing this with the average of the last two samples with a calcium antagonist alone with a paired $t$ test. The effect of botulinum toxin B on basal extracellular dopamine was determined by comparing the average of the last two baseline samples in rats pretreated with a microinfusion of botulinum toxin B with the average of the last two baseline samples from rats pretreated with a saline microinfusion with a $t$ test. 


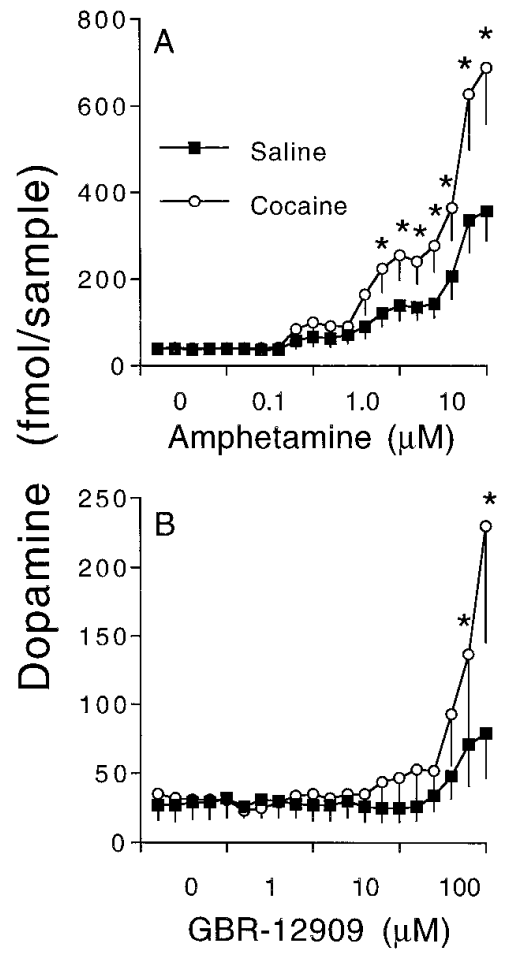

Figure 1. The effect of amphetamine $(A)$ and GBR-12909 $(B)$ on extracellular dopamine in the nucleus accumbens 3 weeks after repeated saline or cocaine treatment. Baseline samples were collected for $100 \mathrm{~min}$, and then three increasing concentrations of amphetamine $(0.1,1.0$, and $10 \mu \mathrm{M})$ or GBR-12909 $(1,10$, and $100 \mu \mathrm{M})$ were incorporated into the dialysis buffer for $100 \mathrm{~min}$ each (400 min experiment total). The data are depicted as the mean \pm SE fmol dopamine per 20 min sample and were statistically evaluated with a two-way repeated measures ANOVA (amphetamine dose $\times$ pretreatment with repeated measures/dose). For amphetamine there was a significant main effect of amphetamine $\left(F_{(19,437)}=34.42 ; p<0.0001\right)$ and a significant amphetamine $\times$ pretreatment interaction $\left(F_{(38,437)}=4.01 ; p<0.0001\right)$. For GBR-12909, there was a significant main effect of amphetamine $\left(F_{(19,285)}=6.31\right.$; $p<0.0001)$ and a significant amphetamine $\times$ pretreatment interaction $\left(F_{(19,285)}=2.104 ; p=0.0051\right)$. *Significant difference from saline $(p<0.05$, Fisher's LSD $)$.

\section{RESULTS}

\section{Behavioral sensitization to cocaine}

Table 1 shows the total horizontal photocell counts for the $2 \mathrm{hr}$ after the first and last injection of daily cocaine or saline. The behavioral response to the last cocaine injection was enhanced relative to the first cocaine administration in all groups. In contrast, there was no consistent change in the behavioral response to saline on the seventh compared to the first injection.

\section{Effect of calcium channel blockers, KN-93, $\mathrm{KN}-92$, and botulinum toxin on basal levels of extracellular dopamine}

Table 2 outlines the influence of the calcium channel blockers, the CaM-KII inhibitor KN-93, the KN-93 control compound $\mathrm{KN}-92$, or botulinum toxin on basal levels of extracellular dopamine in the nucleus accumbens shell. Preliminary doseresponse curves were conducted for the channel blockers and KN-93 to determine a dose that decreased basal extracellular dopamine by $30-50 \%$ from baseline. As shown in Table 2, the calcium channel blockers reduced the extracellular dopamine concentration in the nucleus accumbens by $24-52 \%$ relative to baseline in rats pretreated with either saline or cocaine. Be-

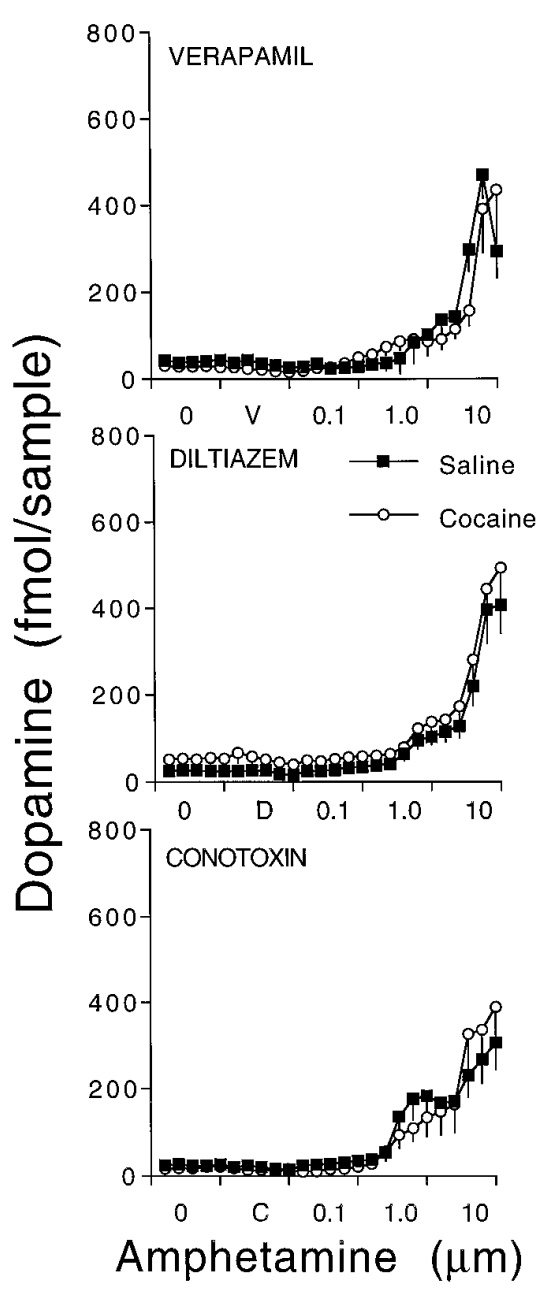

Figure 2. Effects of L-type (100 $\mu \mathrm{M}$ verapamil and $10 \mu \mathrm{M}$ diltiazem) and $\mathrm{N}$-type (1 $\mu \mathrm{M}$ conotoxin) calcium channel antagonists on amphetamineinduced increases in extracellular dopamine in the nucleus accumbens of saline- and cocaine-pretreated rats. After $100 \mathrm{~min}$ of baseline, a calcium antagonist was incorporated into the dialysis buffer for $100 \mathrm{~min}$. For the next $300 \mathrm{~min}$ of the experiment, three increasing doses of amphetamine (0.1-10 $\mu \mathrm{M}, 100 \mathrm{~min}$ each) were included in the dialysis buffer in the presence of the same calcium channel blocker. In all three experiments, there was a significant main effect of amphetamine dose [verapamil $(\mathrm{V}), F_{(24,336)}=15.25, p<0.0001$; conotoxin $(\mathrm{C}), F_{(24,384)}=19.21$, $p<0.0001$; diltiazem (D), $\left.F_{(24,342)}=60.28, p<0.0001\right]$. There were no other significant main effects or interactions.

cause the preliminary dose-response curve for KN-93 did not reveal a change in the basal extracellular levels of dopamine, the dose used was based on $\mathrm{IC}_{50}$ values from in vitro studies allowing for an estimated $10 \%$ efficiency of diffusion across the dialysis membrane (Sumi et al., 1991).

In contrast to the calcium channel antagonists, KN-93, and $\mathrm{KN}-92$, which were administered through the microdialysis probe, botulinum toxin $\mathrm{B}$ was microinfused into the nucleus accumbens before inserting the microdialysis probe. This method of administration was required because the molecular weight of botulinum toxin B $(>100,000)$ is beyond the cutoff for diffusion through the dialysis membrane. As shown in Table 2, this route of administration was effective because botulinum toxin reduced the baseline levels of dopamine in the nucleus accumbens $51-71 \%$ relative to the basal levels obtained in the experiments summarized in Figure 1. 


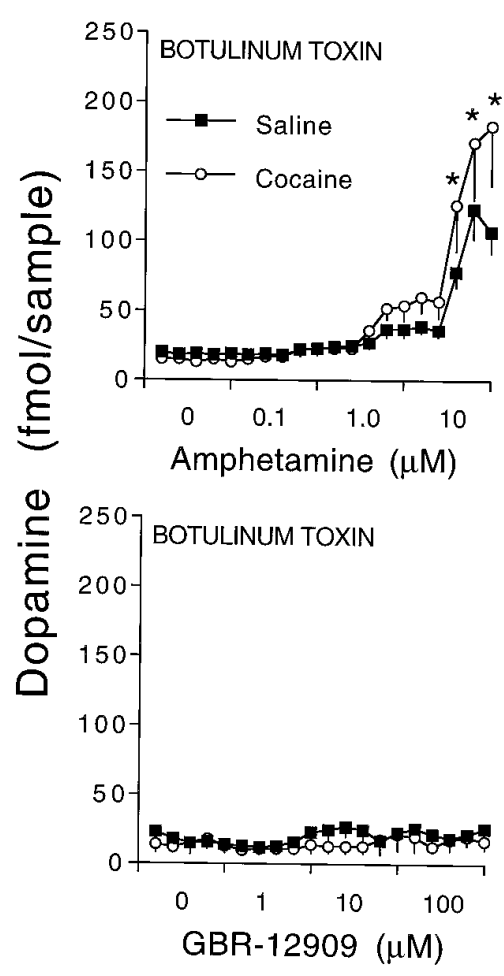

Figure 3. The effect of botulinum toxin B on amphetamine (top)- or GBR-12909 (bottom)-induced increases in extracellular dopamine in the nucleus accumbens of saline- and cocaine-pretreated rats. Botulinum toxin $\mathrm{B}(1.0 \mathrm{ng} / \mu \mathrm{l}, 0.3 \mu \mathrm{l})$ was unilaterally microinfused (via a 33 gauge cannula) into the nucleus accumbens through the microdialysis cannula 15 min before the placement of the microdialysis probe. For the amphetamine experiment, a two-way ANOVA revealed a significant main effect of amphetamine dose $\left(F_{(19,285)}=24.28, p<0.0001\right)$ and a significant interaction between treatment groups and dose of amphetamine $\left(F_{(19,285)}=1.59, p=0.058\right)$. For the GBR-12909 experiment, there was a significant main effect of GBR-12909 dose $\left(F_{(19,190)}=2.12\right.$, $p=0.0058)$; there were no other significant main effects or interactions. *Significant difference from saline $(p<0.05$, Fisher's LSD).

\section{Effect of amphetamine or GBR-12909}

The data outlined in Figure $1 A$ demonstrate that amphetamine produced a dose-dependent increase in extracellular dopamine in the nucleus accumbens shell and that this effect was significantly enhanced in animals pretreated with cocaine. Likewise, the capacity of GBR-12909 to increase extracellular dopamine was enhanced in cocaine- relative to saline-pretreated rats (Fig. 1B).

\section{Effect of calcium channel antagonists}

Figure 2 demonstrates that blockade of calcium channels with verapamil (L-type), diltiazem (L-type), or $\omega$-conotoxin (N-type) prevented the augmented increase in extracellular dopamine in cocaine-pretreated animals. None of the calcium channel blockers altered the capacity of amphetamine to increase extracellular dopamine in rats repeatedly given injections of saline.

\section{Effect of botulinum toxin B}

Figure 3 shows that, even though the maximal effect of amphetamine was blunted by pretreatment with botulinum toxin $\mathrm{B}$, the augmented increase in extracellular dopamine among cocainesensitized rats was unaffected. In contrast, botulinum toxin B pretreatment eliminated the capacity of GBR-12909 to elevate extracellular dopamine in both the cocaine and saline groups.

\section{Effect of KN-93 and KN-92}

Figure 4 illustrates that, similar to the calcium channel antagonists (see Fig. 2), inhibition of CaM-KII with KN-93 prevented the augmented increase in extracellular dopamine induced by amphetamine in cocaine-pretreated animals. KN-93 also inhibited the augmented increase in extracellular dopamine produced by GBR-12909 in subjects pretreated with cocaine. KN-93 did not alter the capacity of amphetamine or GBR-12909 to elevate extracellular dopamine in the nucleus accumbens of salinepretreated subjects. In contrast, $\mathrm{KN}-92$, the control compound for $\mathrm{KN}-93$, did not influence the amphetamine-induced increase in extracellular dopamine in the nucleus accumbens in salinepretreated rats or the augmented release of dopamine observed in cocaine-sensitized rats.

\section{Histology}

Figure 5A depicts microdialysis probe placements in the shell of the nucleus accumbens. The dialysis probes were located in the medial compartment of the shell, not in the lateral limb. Many probes were at the lateral edge of the shell adjacent to the core. Also, in several cases a portion of the active region of the probes was located in the ventral neostriatum. Figure 5, $B$ and $C$, shows micrographs depicting probe tracts in the nucleus accumbens of rats treated with KN-93 plus GBR-12909 and botulinum toxin B plus amphetamine through the probe, respectively. Note the lack of neurotoxicity after either treatment other than the mechanical damage produced by the microdialysis probe.

\section{DISCUSSION}

The present results demonstrate that the enhanced increase in extracellular dopamine in the nucleus accumbens shell of cocainesensitized rats arises from the induction of a requirement for calcium- and CaM-KII-dependent mechanisms. This finding is consistent with the calcium-dependent increase in extracellular dopamine induced by dopamine reuptake blockers, such as GBR12909. However, because the amphetamine-induced increase in extracellular dopamine occurs in the absence of calcium-mediated vesicular exocytosis in saline-pretreated rats, the calciumdependent portion of the amphetamine neurochemical response represents a shift in the mechanism of action of this drug after the repeated administration of cocaine.

\section{Behavioral sensitization and dopamine in the nucleus accumbens}

Consistent with previous findings (Pierce and Kalivas, 1995), the present results indicate that the capacity of locally applied amphetamine to enhance dopamine transmission in the nucleus accumbens shell is enhanced in cocaine-pretreated rats. Our data also indicate that the administration of the selective dopamine reuptake blocker, GBR-12909, through the dialysis probe results in an amplified increase in extracellular dopamine among cocainerelative to saline-pretreated animals. It is important to note that these results were obtained 3 weeks after the last repeated injection of cocaine and that these changes in dopamine transmission often are not observed during the first few days after the cessation of a repeated psychostimulant treatment regimen (Segal and Kuzcenski, 1992a,b; Kalivas and Duffy, 1993; Wolf et al., 1993; Pierce and Kalivas, 1995; Heidbreder et al., 1996).

\section{Role of calcium}

The present data clearly indicate a role for L- and N-type calcium conductances in the augmented increase in extracellular dopamine induced by amphetamine or GBR-12909 in the nucleus 


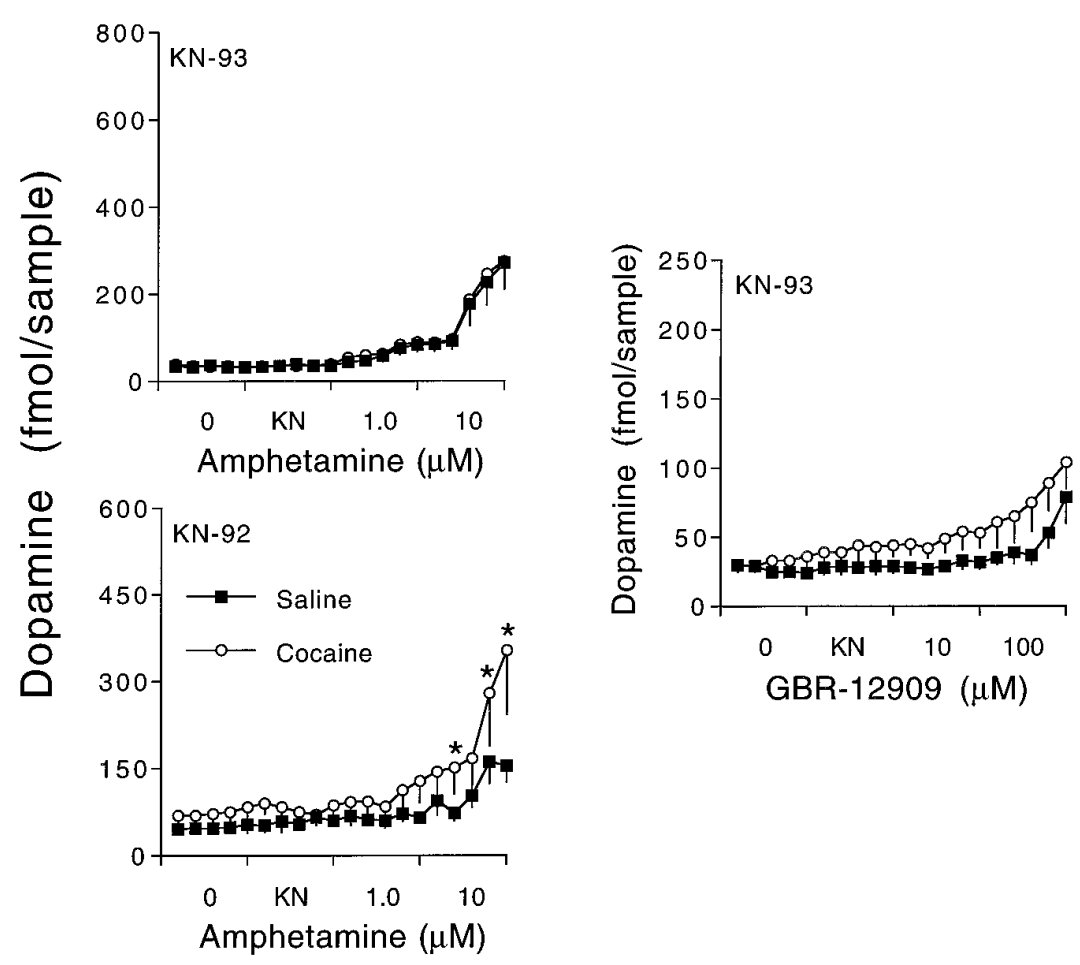

Figure 4. The effect of the CaM-KII blocker, KN-93, on amphetamine- or GBR-12909-induced increases in extracellular dopamine in the nucleus accumbens of saline- and cocaine-pretreated rats. Baseline samples were collected for $100 \mathrm{~min}$, followed by $100 \mathrm{~min}$ of $\mathrm{KN}-93(10 \mu \mathrm{M})$. For the remaining $300 \mathrm{~min}$ of the experiment, three increasing concentrations of amphetamine $(0.1,1.0$, and $10 \mu \mathrm{M})$ or GBR$12909(1,10$, and $100 \mu \mathrm{M})$ were incorporated into the dialysis buffer for $100 \mathrm{~min}$ each with $10 \mu \mathrm{M} \mathrm{KN}-93$. For the amphetamine experiment, there was a significant main effect of amphetamine dose $\left(F_{(19,285)}=26.25 ; p<0.0001\right)$, with no other significant treatment effects or interactions. For the GBR-12909 experiment, there was a significant main effect of GBR-12909 dose $\left(F_{(19,475)}=9.77 ; p<\right.$ 0.0001 ), with no other significant treatment effects or interactions. The effects of the KN-93 control compound, KN-92, also were assessed on amphetamine-induced increases in extracellular dopamine in the nucleus accumbens of salineand cocaine-pretreated rats. The design of the experiment was identical to the amphetamine experiment described above, except that KN-92 $(10 \mu \mathrm{M})$ was substituted for $\mathrm{KN}$ 93. The analysis of this experiment revealed a significant main effect of amphetamine dose $\left(F_{(19,285)}=8.77 ; p<\right.$ $0.0001)$ and a significant amphetamine $\times$ treatment interaction $\left(F_{(19,285)}=1.59 ; p=0.05\right)$. * Significant difference from saline $(p<0.05$, Fisher's LSD). accumbens of cocaine-sensitized rats. The results of the GBR12909 experiments are consistent with evidence that impairing impulse flow or presynaptic calcium influx severely impairs the ability of dopamine reuptake blockers to increase extracellular dopamine (Carboni et al., 1989; Westerink et al., 1989). In contrast, the elimination of the sensitized portion of the amphetamine-induced increase in dopamine in cocainepretreated rats stands in sharp contrast to the augmentation in dopamine transmission induced by amphetamine in salinepretreated rats, which is completely unaffected by the coadministration of calcium channel antagonists (see Fig. 2).

The distinction between the mechanisms of action of GBR12909 and amphetamine was verified in the experiments in which animals were pretreated with an intra-accumbens microinjection of botulinum toxin $\mathrm{B}$, which cleaves synaptobrevin, thereby preventing vesicular fusion with the plasma membrane (Burgoyne and Morgan, 1995; Schweizer et al., 1995). Botulinum toxin administration abolished the increase in extracellular dopamine induced by GBR-12909 in both cocaine- and saline-pretreated rats. The elimination of the GBR-12909-induced increases in dopamine by botulinum toxin $\mathrm{B}$ was expected and verifies the effectiveness of the dose used for disrupting vesicular exocytosis. In contrast, impairing calcium-mediated vesicular exocytosis had no influence on the ability of amphetamine to augment the increase in extracellular dopamine in cocaine-sensitized rats. However, botulinum toxin B attenuated the maximal increase in extracellular dopamine induced by amphetamine in both the cocaine and saline groups, suggesting that the amphetamineinduced increase in extracellular dopamine may be partially calcium dependent. This finding is inconsistent with the mechanism of action of amphetamine being mediated solely by reverse transport (Fisher and Cho, 1979; Liang and Rutledge, 1982). Higher concentrations of amphetamine have been proposed not only to promote reverse transport of dopamine into the extracellular space, but also to prevent the uptake of dopamine into the cytosol (Kuzcenski, 1983). Thus, a component of the increase in extracel- lular dopamine induced by amphetamine may depend on vesicular exocytosis. Regardless of the role exocytosis may play in maintaining the increase in extracellular dopamine after the administration of high doses of amphetamine, the present data clearly demonstrate that the augmented increase in dopamine in cocainepretreated subjects was not blocked by botulinum toxin B and is, therefore, independent of vesicular exocytosis.

\section{Role of CaM-KII}

The CaM-KII inhibitor KN-93 abolished the augmented increase in extracellular dopamine produced by either amphetamine or GBR-12909 in rats sensitized to cocaine. The induction of a CaM-KII-dependent mechanism in the expression of behavioral sensitization to psychostimulants is consistent with biochemical measurements showing increased calmodulin activity in rats pretreated with daily amphetamine (Gnegy et al., 1991). Although the present data do not indicate which CaM-KII phosphorylated protein(s) is mediating the changes in amphetamine- and GBR12909-induced increases in extracellular dopamine, two potential mechanisms can be considered. A recent in vitro study reported that the $V_{\max }$ of the plasmallemal dopamine transporter is enhanced in the presence of calcium, and that this calciumdependent enhancement of dopamine uptake is regulated by CaM-KII (Uchikawa et al., 1995). These results suggest that the augmented effect of amphetamine among sensitized rats may be due to a CaM-KII-mediated enhancement of amphetamine uptake by the plasmallemal dopamine transporter and an associated increase in the reverse transport of dopamine. However, the fact that CaM-KII activity was required for the augmented effect of GBR-12909 in the present study argues against a role for phosphorylation of dopamine transporters. That is, because GBR12909 binds to the transporter but is not transported, a CaM-KII induced increase in transport velocity is not likely to be involved in the enhanced increase in extracellular dopamine induced by GBR-12909 in the nucleus accumbens of cocaine-sensitized rats.

A second possibility resides in the influence of CaM-KII on 

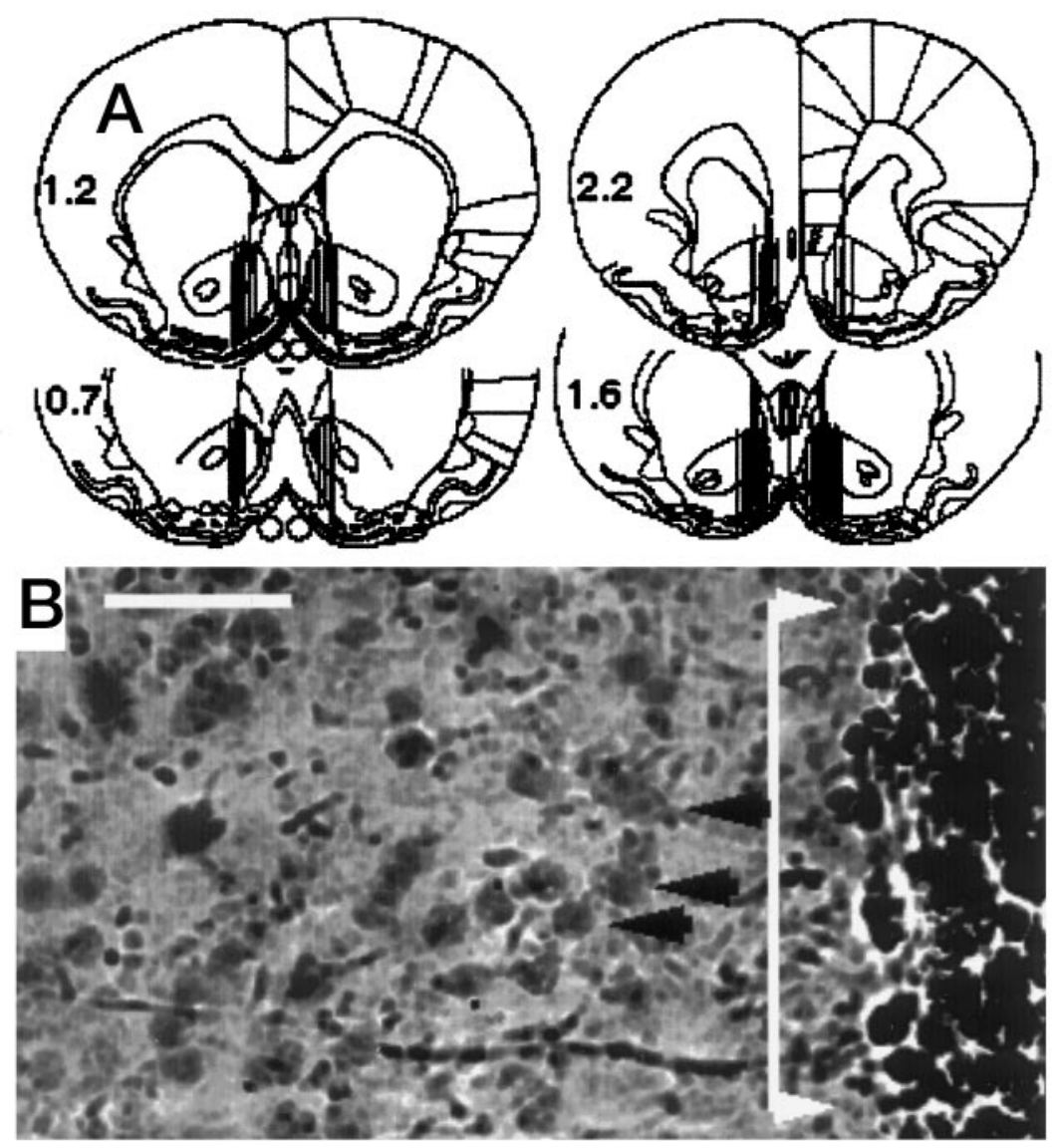

Figure 5. Histological evaluation of dialysis probe placements in the medial nucleus accumbens. $A$, Composite of the location of all dialysis probe tracts used in data analysis. $B$, Micrograph taken at the level of the nucleus accumbens. In this animal, KN-93 and GBR-12909 were simultaneously incorporated into the microdialysis buffer. $C$, Micrograph of the nucleus accumbens of a rat that was microinfused with botulinum toxin B; amphetamine subsequently was applied locally to the nucleus accumbens. Scale bar, $100 \mu \mathrm{M}$. Note the lack of neurotoxicity in $B$ and $C$, other than the mechanical damage produced by the microdialysis probe. The white arrows indicate the mechanical damage produced by the microdialysis probe. The black arrows point to intact cells located near the microdialysis probe.

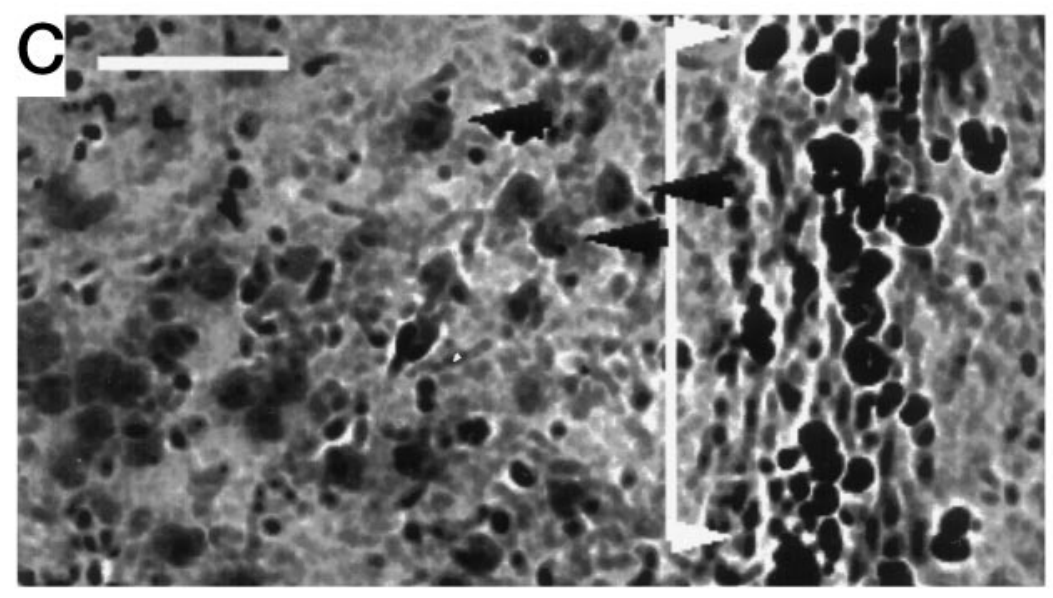

synaptic vesicles. CaM-KII promotes the undocking of vesicles from cytoskeletal proteins in preparation for exocytosis by phosphorylating synapsin I (Lin et al., 1990). Recently, CaM-KIIdependent phosphorylation of synapsin I was found to be augmented in rats pretreated with repeated amphetamine (Iwata et al., 1996). An amplification of this CaM-KII dependent transduction pathway in rats behaviorally sensitized to cocaine may explain the augmented capacity of GBR-12909 to elevate extracellular dopamine. Because synaptic vesicles must undock before fusion with the plasmallemal membrane (Burgoyne and Morgan, 1995; Schweizer et al., 1995) and vesicular fusion mediates the increase in extracellular dopamine after dopamine transporter blockade by GBR-12909, increasing the proportion of undocked vesicles may mediate the enhanced effect of GBR-12909 on dopamine trans- mission in cocaine-pretreated rats. The manner in which the CaM-KII-mediated undocking of synaptic vesicles augments the effects of amphetamine is less apparent. One possibility is that the vesicular dopamine transporter may be more readily accessed by amphetamine in undocked vesicles, thereby increasing the availability of cytoplasmic dopamine for reverse transport.

\section{Clinical implications}

The data presented herein show that repeated cocaine initiates an enduring requirement for calcium and the activation of CaM-KII for the augmented increase in dopamine in the nucleus accumbens induced by amphetamine or GBR-12909. A pathophysiological change in dopamine transmission in the nucleus accumbens is a major candidate in the etiology of psychostimulant-induced 
psychiatric disorders (Segal et al., 1981; Post and Weiss, 1988). Behavioral sensitization and dopamine transmission in the nucleus accumbens are also implicated in the abuse liability of psychostimulants (Robinson and Berridge, 1993). Whereas a role for calcium transduction mechanisms in psychostimulant-induced psychopathologies remains to be established, several preclinical studies report that calcium channel antagonists influence psychostimulant self-administration and conditioned place preference in a manner similar to dopamine antagonists (Pani et al., 1991; Martellotta et al., 1994; Rosenzweig-Lipson and Barrett, 1995). Collectively, these results suggest that drugs that act on calcium conductances and associated transduction pathways might serve as potentially effective therapeutic agents for treating psychostimulant abuse and possibly psychostimulant-induced psychiatric disorders.

\section{REFERENCES}

Burgoyne RD, Morgan A (1995) $\mathrm{Ca}^{2+}$ and secretory-vesicle dynamics. Trends Neurosci 18:191-196.

Calabresi P, Pisani a Mercuri NB, Bernardi G (1994) Post-receptor mechanisms underlying striatal long-term depression. J Neurosci 14:4871-4881.

Carboni E, Imperato A, Perezzani L, Di Chiara G (1989) Amphetamine, cocaine, phencyclidine and nomifensine increase extracellular dopamine concentrations preferentially in the nucleus accumbens of freely moving rats. Neuroscience 28:653-661.

Di Chiara G (1995) The role of dopamine in drug abuse from the perspective of its role in motivation. Drug Alcohol Depend 38:95-137.

Ellinwood EH (1967) Amphetamine psychosis. I. Description of the individuals and process. J Nerv Ment Dis 144:273-283.

Fischer JF, Cho AK (1979) Chemical release of dopamine from striatal homogenates: evidence for an exchange diffusion model. J Pharmacol Exp Ther 208:203-209.

Gnegy ME, Hewlett GHK, Yee SL, Welsh MJ (1991) Alterations in calmodulin content and localization in areas of rat brain after repeated intermittent amphetamine. Brain Res 562:6-12.

Heidbreder CA, Thompson AC, Shippenberg TS (1996) Role of extracellular dopamine in the initiation and long-term expression of behavioral sensitization to cocaine. J Pharmacol Exp Ther 278:490-502.

Iwata S, Hewlett GHK, Ferrell ST, Czernik AJ, Meiri K, Gnegy ME, (1996) Increased in vivo phosphorylation state of neuromodulin and synapsin I in striatum from rats treated with repeated amphetamine. J Pharmacol Exp Ther 278:1428-1434.

Kalivas PW, Duffy P (1993) Time course of extracellular dopamine and behavioral sensitization to cocaine. I. Dopamine axon terminals. J Neurosci 13:266-275.

Karler R, Turkanis SA, Partlow LM, Calder LD (1991) Calcium channel blockers in behavioral sensitization. Life Sci 49:165-170.

Koob GF, Bloom FE (1988) Cellular and molecular mechanisms of drug dependence. Science 242:715-723.

Kuzcenski R (1983) Biochemical actions of amphetamine and other stimulant. In: Stimulants: neurochemical, behavioral and clinical perspectives (Creese I, ed), pp 31-61. New York: Raven.

Liang NY, Rutledge CO (1982) Comparison of the release of $\left[{ }^{3} \mathrm{H}\right]$ dopamine from isolated corpus striatum by amphetamine, fenfluamine and unlabeled dopamine. J Pharmacol Exp Ther 202:544-557.

Lin JW, Sugimori M, Llinas RR, McGuiness TL, Greengard P (1990) Effects of synapsin I and calcium/calmodulin-dependent protein kinase II on spontaneous neurotransmitter release in the squid giant synapse. Proc Natl Acad Sci USA 82:8257-8261.

Lisman J (1994) The CaM kinase II hypothesis for the storage of synaptic memory. Trends Neurosci 17:406-412.

Martellotta MC, Kuzmin A, Muglia P, Gessa GL, Fratta W (1994) Effections of the calcium antagonist isadipine on cocaine intravenous self-administration in rats. Psychopharmacology 113:378-380.

Martin-Iverson MT, Reimer AR (1994) Effects of minodipine and/or haloperidol on the expression of conditioned locomotion and sensitization to cocaine in rats. Psychopharmacology 114:315-320.

Nestler EJ (1992) Molecular mechanisms of drug addiction. J Neurosci 12:2439-2450.

Nomikos GG, Damsma G, Wenkstern D, Fibiger HC (1990) In vivo characterization of locally applied dopamine uptake inhibitors by striatal microdialysis. Synapse 6:106-112.

Pani L, Carboni S, Kusmin A, Gessa GL, Rossetti ZL (1990) Nimodipine inhibits cocaine-induced dopamine release and motor stimulation. Eur J Pharmacol 176:245-246.

Pani L, Kuzmin A, Martellotta MC, Gessa GL, Fratta W (1991) The calcium antagonist PN 200-110 inhibits the reinforcing properties of cocaine. Brain Res Bull 26:445-447.

Paulson PE, Robinson TE (1995) Amphetamine-induced timedependent sensitization of dopamine neurotransmission in the dorsal and ventral striatum: a microdialysis study in behaving rats. Synapse 19:56-65.

Paxinos G, Watson C (1986) The rat brain in stereotaxic coordinates. New York: Academic.

Pierce RC, Kalivas PW (1995) Amphetamine produces sensitized increases in locomotion and extracellular dopamine preferentially in the nucleus accumbens shell of rats administered repeated cocaine. J Pharmacol Exp Ther 275:1019-1029.

Post RM, Weiss SRB (1988) Sensitization and kindling: implications for the evolution of psychiatric symptomatology. In: Sensitization in the nervous system (Kalivas PW, Barnes CD, eds), pp 257-292. Caldwell, NJ: Telford.

Robinson TE, Berridge KC (1993) The neural basis of drug craving: an incentive-sensitization theory of addiction. Brain Res Rev 18:247-291.

Robinson TE, Whishaw IQ (1988) Normalization of extracellular dopamine in the striatum following recovery from a partial unilateral 6-OHDA lesion of the substantia nigra: a microdialysis study in freely moving rats. Brain Res 450:209-224.

Rosenweig-Lipson S, Barrett JE (1995) Modification of the behavioral effects of $( \pm)$ BAY k 8644, cocaine and d-amphetamine by L-type calcium channel blockers in squirrel monkeys. J Pharmacol Exp Ther 274:842-851.

Schweizer FE, Betz H, Augustine GJ (1995) From vesicle docking to endocytosis: intermediate reactions of exocytosis. Neuron 14:689-696.

Segal DS, Kuczenski R (1992a) In vivo microdialysis reveals a diminished amphetamine-induced dopamine response corresponding to behavioral sensitization produced by repeated amphetamine pretreatment. Brain Res 521:330-332.

Segal DS, Kuczenski R (1992b) Repeated cocaine administration induces behavioral sensitization and corresponding decreased extracellular dopamine responses in caudate and accumbens. Brain Res 577:351-355.

Segal DS, Geyer MA, Schuckit MA (1981) Stimulant-induced psychosis: an evaluation of animal models. In: Essays in neurochemistry and neuropharmacology, Vol 5 (Youdim MBH, Lovenberg W, Sharman DF, Lagnado JR, eds), pp 95-129. London: Wiley.

Seiden LS, Sabol KE, Ricuarte GA (1993) Amphetamine: effects on catecholamine systems and behavior. Annu Rev Pharmacol Toxicol 33:639-677.

Sumi M, Kiuchi K, Ishikawa T, Ishii A, Hagiwara M, Nagatsu T, Hidaka $\mathrm{H}$ (1991) The newly synthesized selective $\mathrm{Ca}^{2+} /$ calmodulin dependent protein kinase II inhibitor KN-93 reduces dopamine contents in PC12h cells. Biochem Biophys Res Commun 181:968-975.

Uchikawa T, Kiuchi Y, Yura A, Nakachi N, Yamazaki Y, Yokomizo C, Oguchi K (1995) $\mathrm{Ca}^{2+}$-dependent enhancement of $\left[{ }^{3} \mathrm{H}\right]$ dopamine uptake in rat striatum: possible involvement of calmodulin-dependent kinases. J Neurochem 65:2065-2071.

Van der Zee P, Koger HS, Gootjes J, Hespe W (1980) Aryl 1,4dialk(en)ylpiperazines as selective and very potent inhibitors of dopamine uptake. Eur J Med Chem Chim Ther 15:363-370.

Warburton EC, Mitchell SN, Joseph MH (1996) Calcium dependence of sensitized dopamine release in rat nucleus accumbens following amphetamine challenge: implications for the disruption of latent inhibition. Behav Pharmacol 7:119-129.

Westerink BHC, Hofsteede RM, Tuntler J, de Vries JB (1989) Use of calcium antagonism for the characterization of drug-evoked dopamine release from the brain of conscious rats determined by microdialysis. J Neurochem 52:722-729.

Wise RA, Bozarth MA (1987) A psychomotor stimulant theory of addiction. Psychol Rev 94:469-492.

Wolf ME, White FJ, Nassar R, Brooderson RJ, Khansa MR (1993) Differential development of autoreceptor subsensitivity and enhanced dopamine release during amphetamine sensitization. J Pharmacol Exp Ther 264:249-255. 